\title{
Assessment of Clustered Renewable Energy Systems Interconnected with Low-Voltage Distribution Networks
}

\author{
Tsai-Hsiang Chen, Ying Lin, Ting-Yen Hsieh \\ Department of Electrical Engineering \\ National Taiwan University of Science and Technology \\ Taipei, Taiwan, R.O.C. \\ thchen@mail.ntust.edu.tw, M9807107@mail.ntust.edu.tw, \\ D9607103@mail.ntust.edu.tw
}

\author{
Wei-tzer Huang \\ Department of Industrial Education and Technology \\ National Changhua University of Education \\ Changhua County, Taiwan, R.O.C. \\ vichuang@cc.ncue.edu.tw
}

\begin{abstract}
As assessment of clustered renewable energy systems (CRESs) interconnected with low-voltage distribution system have been discussed in this paper. A direct search method is proposed to evaluate the maximum allowable capacity of CRESs in the low-voltage distribution system in Taiwan. Simulation results have shown that the arbitrary installation for CRESs would damage the customer loads and significantly increase the costs on system operation and maintenance. The simulation results and analysis methods are of value to engineer for planning and designing the suitable CRESs in a low voltage distribution network.
\end{abstract}

Index Terms-Clustered renewable energy systems(CRESs); Low-voltage distribution system; Direct search method; Planning and designing.

\section{INTRODUCTION}

In 1992, the first United Nation framework convention on climate change was adopted in New York. Following with the Kyoto protocol in Japan 1998 and the Durban conference in South African 2011, the problems such as energy crisis and greenhouse emission have caused a significant concerned worldwide. Many energy policies and research projects focused on the energy-saving and the clean energy have been presented in recent years. To reduce the electricity which is produced by burning the fossil fuels, the distributed generation resources (DGs) are gaining in significance in the last two decades. In the Spanish, by the end of 2010, there is around $33 \%$ of total electricity production are required to produce by those distributed generation [1]. The first zero-energy office building integrated grid-connected rooftop BIPV to meet its demand for energy was established in Singapore [2]. A demonstrative project on grid-interconnection of clustered photovoltaic power generation systems, which including more than 550 residential PV system, was built in Ota city in Japan [3]. Therefore, one development of renewable energy resources is toward clustered DGs installed in a specific small area, which is named as the clustered renewable energy systems (CRESs) in this paper.
As the CRESs have been widely installed in the power distribution network, some measurable problems on the system operation, power quality, and power regulation start to arise. To solve these problems, many research papers have been published to reduce the adverse effects. An assessment on voltage profiles in residential neighborhoods in the presence of PV systems is published in [4]. A study to assess the impact of fluctuating solar irradiance on the grid voltage is provided in [5]. The difference among local interconnection rules for DGs, local geographic characteristics, national grid code, etc. makes the provided simulation results misfit the case in Taiwan. Therefore, the paper is focus on the low-voltage distribution system in Taiwan to evaluate the effects of CRESs on the system performance and search for the maximum allowable capacity of CRESs. Some important indices such as line thermal limits and allowable maximum voltage deviation are all taken into account in the paper. This paper is organized as follows. The mathematical models of DGs and interconnection rules for DGs are introduced in Section 2. The definitions of simulation scenarios are presented in Section 3. Simulation and discussion are introduced in Section 4. Finally, a brief conclusion is drawn

\section{MATHEMATICAL MODELS OF DGS AND INTERCONNECTION RULES FOR DGS}

\section{A. Mathematical models of $D G s$}

There are three mathematical models are commonly used to represent the performance of DGs in the distribution system analysis. That is, the constant-power-factor model, the constant-voltage model, and the induction-machine model. In recent years, the DGs are ruled to control their output power and reactive component to reduce the adverse impact on the distribution system. Here, the constant-power-factor model is chosen to simulate the operating characteristic of DGs. The DGs injection current for the constant-power-factor model is given in (1).

$$
I=(S / V)^{*} \angle \delta-\theta
$$


where

$V:$ Bus voltage at the interconnection point.

$S$ : DGs generated apparent power.

$I$ : Injection current source at the interconnection point

$\delta$ : The phase angle of the grid driving-point impedance

$\theta:$ The phase angle between the output voltage and current of DGs

\section{B. Interconnecting Rules for DGs}

According to the interconnection rule for DGs and National Electric Code in Taiwan, the rules related to DGs interconnection are outlined as follows.

- For the DGs with capacity under $100 \mathrm{~kW}$ can directly interconnect with the single-phase three-wires 110/220 $\mathrm{V}$ distribution system, three-phase four-wires $220 / 380$ V distribution system, or the distribution system with higher voltage level.

- The maximum capacity of DGs installed in the singlephase low voltage distribution system should not exceed $20 \mathrm{kVA}$.

- The voltage variation at the point of common coupling (PCC) should not be more than $\pm 2.5 \%$ due to the parallel operation of DGs with the distribution grid.

\section{DIRECT SEARCH METHOD FOR DETERMINATION OF THE MAXIMUM ALLOWABLE CAPACITY OF CRESS}

To evaluate the maximum allowable capacity of DGs among CRESs, a direct search method was proposed in this paper. The bisection search method is used to calculate the possible installed capacity of CRESs. The convergence tolerance is set at $\pm 0.05 \%$ bus voltage in per unit. Equation (2) is used to assess steady-state voltage deviations due to DGs interconnections with distribution networks.

$$
d \%=S_{D G} / S_{\text {S.C. }} \times \cos (\phi+\theta) \times 100 \%
$$

where $d \%$ denotes the steady-state voltage deviation as a percentage of the nominal voltage; $S_{S . C .}$ is the network short circuit capacity at the point of DG interconnection; $S_{D G}$ stands for the rated apparent power of DG at 1-min. time interval; and $\phi$ and $\theta$ represent the phase angle of the grid driving-point impedance and the phase angle between the output voltage and current of DG, respectively.

Equation (2) can be rewritten as

$$
P_{D G}=d \times S_{\text {S.C. }} / \cos (\phi+\theta) \times \cos \theta
$$

where $P_{D G}$ is the maximum permissible DGs capacity at that point under the given conditions.

Different from the past research to determine the maximum allowable capacity of DGs at a specific bus, the proposed method is developed for the multiple DGs uniformly installed in the low voltage distribution system. In that case, the short circuit capacity of the utility system, distribution transformation (DT) capacity, line impedance, loading, and locations for installation of DGs would have a great impact on the determination of maximum allowable capacity of DGs among CRESs. The limitations on the line thermal limits and the restrictions on the steady-state bus voltage deviation should be obeyed. The flow chart for the proposed method is shown in Fig.1.

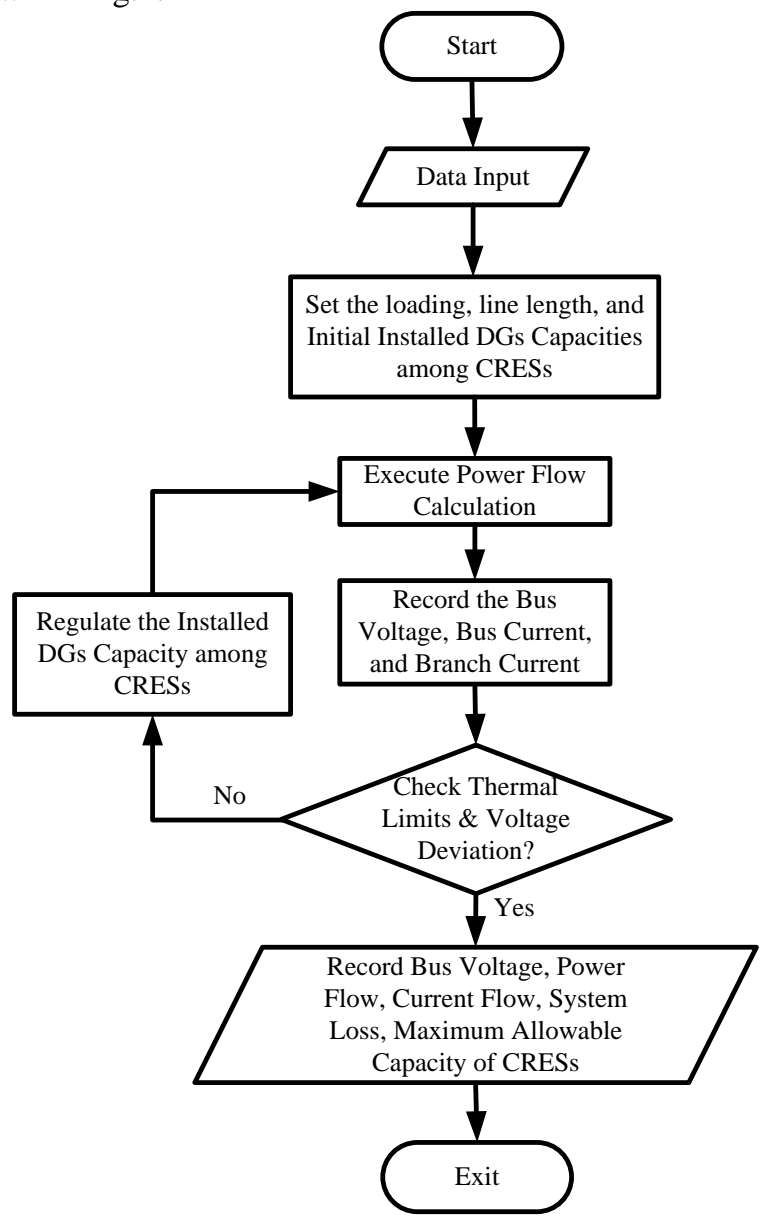

Fig. 1. Flow Chart for the proposed direct search method

\section{SIMULATION AND DISCUSSION}

There are 16 simulation scenarios are provided in this section to evaluate the possible impacts of the CRESs on the low voltage distribution system. There are another 12 simulation scenarios are given to search for the maximum allowable capacity of CRESs in the low voltage distribution system in Taiwan. All simulations are realized by the MATLAB software. Detailed explanation are introduced as follows.

\section{A. Simulation Scenarios}

The sample system with a $50 \mathrm{kVA}$ rating distribution transformer is shown in fig.2. In the sample system, the primary voltage rating is $11.4 \mathrm{kV}$, the distribution transformer can provide the three-wire connection to designate two $110 \mathrm{~V}$ mid-tap voltage with a $220 \mathrm{~V}$ full-winding voltage. There are 12 customers are uniformly distributed along the secondary feeders. The distance for the secondary feeder is $30 \mathrm{~m}$ or $95 \mathrm{~m}$, 
and the distance between each customer are set 5 or $30 \mathrm{~m}$ depend on the feeder length. There are two extreme loading conditions are realized in the simulation. Three kinds of CRESs are simulated in this section. First is the CRESs with the pure PV system, the second is the CRESs with the pure Wind power generator, the third is the CRESs with the combination of PV and Wind power generator. The detailed simulation scenarios for the sample system are summarized in table 1 .

\section{B. Voltage profile along the secondary feeder}

As the CRESs interconnected with low voltage distribution network, the power flow and voltage profile would be changed depend on the DGs generation, customer loads, and etc.. Unsuitable bus voltage might not only decrease the load efficiency, reduce devices

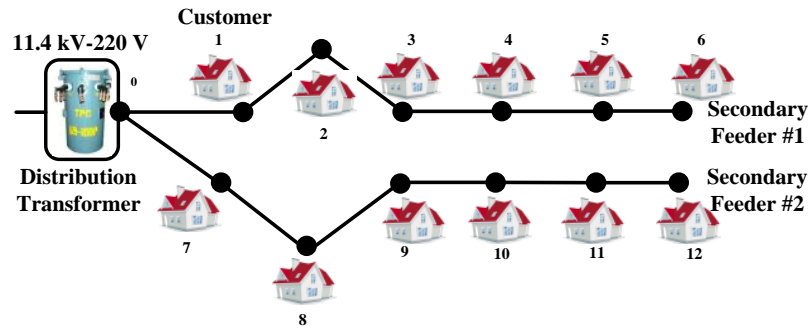

Fig. 2. Schematic diagram for the low-voltage distribution system

Table 1 Simulation scenarios for the sample system

\begin{tabular}{|c|c|c|c|}
\hline \multicolumn{2}{|c|}{ Customer Load } & $\begin{array}{c}\text { Heavy } \\
\text { Load }\end{array}$ & $\begin{array}{c}\text { Light } \\
\text { Load }\end{array}$ \\
\hline \multirow{2}{*}{ CRe Scenario } & $0 \mathrm{~kW}$ & Scenario \#1 & Scenario \#9 \\
\hline \multirow{2}{*}{ Basic Case } & $2 \mathrm{~kW}$ & Scenario \#2 & Scenario \#10 \\
\cline { 2 - 4 } & $4 \mathrm{~kW}$ & Scenario \#3 & Scenario \#11 \\
\cline { 2 - 4 } $\begin{array}{c}\text { CRESs with Wind } \\
\text { power generator }\end{array}$ & $6 \mathrm{~kW}$ & Scenario \#4 & Scenario \#12 \\
\cline { 2 - 4 } & $3 \mathrm{~kW}$ & Scenario \#5 & Scenario \#13 \\
\cline { 2 - 4 } $\begin{array}{c}\text { CRESs with } \\
\text { combination of PV } \\
\text { and Wind power } \\
\text { generator }\end{array}$ & $5 \mathrm{~kW}$ & Scenario \#6 & Scenario \#14 \\
\hline
\end{tabular}

life cycle, and increase operation and maintenance costs. The severer results are occurred in the light load conditions, the partial simulation results for the voltage profile along the secondary feeder is shown in Fig. 3. Results indicate that bigger installed capacity of CRESs would make larger voltage rise, especially for the voltage at feeder end. According to the limitations on the steady state bsu voltage variation at the point of common coupling (PCC), the maximum allowable capacity for the sample system is around $5 \mathrm{~kW}$.

\section{Branch current along the secondary feeder}

With the increasing generation from CRESs, the secondary feeder might out of thermal limitation in some condition. Here, the allowable current capacity for the secondary feeder is 115 A. Simulation results indicate that the maximum allowable capacity for the sample system is around $3 \mathrm{~kW}$, as shown in Fig.4.

\section{Distribution transformer loading}

Generally, the distribution transformer is applied to transform the high voltage at the primary side to the low voltage at the secondary side. In the past, there is only one way to supply power from the distribution transformer to each customers. With the development of CRESs, the two way power flow among the customers and the utility system have become possible. Those reverse powers generated from CRESs might make the distribution transformer overloading in some condition. To assess the impacts of installed capacity of CRESs on the distribution network, some simulation results are shown in Fig.5. Results indicates that the transformer overloading were occurred in scenario number \#8, \#12, \#15, and \#16.

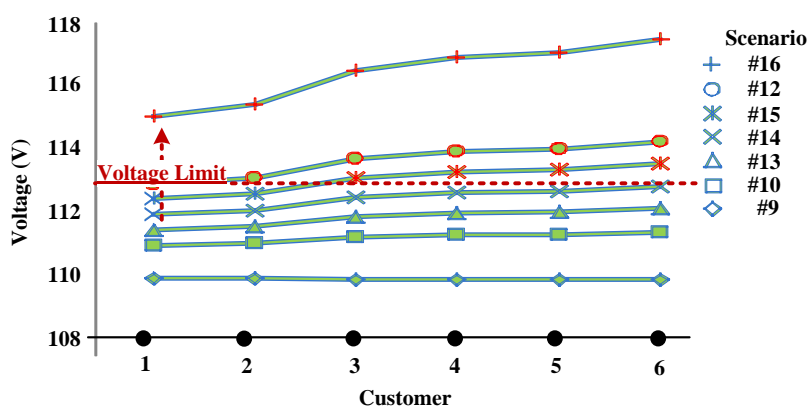

Fig. 3. Voltage profile along the secondary feeder

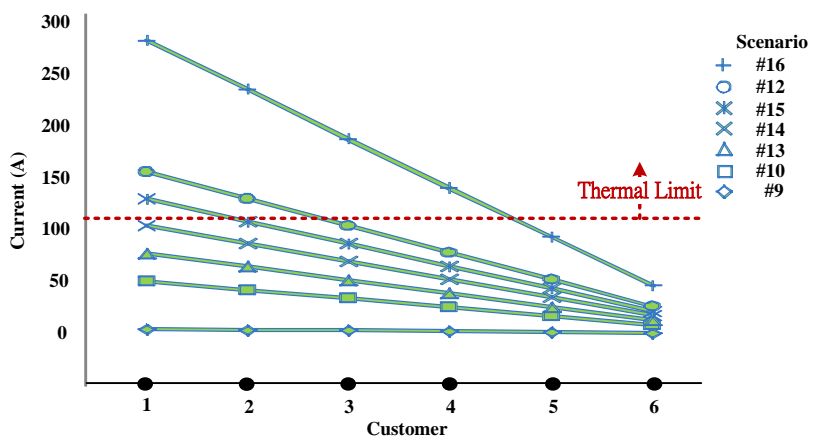

Fig. 4. Branch current along the secondary feeder

\section{E. The maximum allowable capacity of CRESs}

To cover most of the low-voltage distribution networks in Taiwan, there are 12 case scenarios are discussed in this section, as shown in table 2. All simulations are realized by the proposed direct search method mentioned in the Section 3. Simulation results are shown in table 3. Simulation results indicates that the maximum allowable capacity of CRESs is $4.59 \mathrm{~kW}$ for the feeder length with $30 \mathrm{~m}$, and the maximum allowable capacity of CRESs is $2.34 \mathrm{~kW}$ for one with $95 \mathrm{~m}$. That is, the maximum allowable capacity of CRESs for different feeder length $(30 \mathrm{~m}$ and $95 \mathrm{~m})$ is around $2.25 \mathrm{~kW}$. And, the maximum allowable capacity of CRESs for different customer load conditions (heavy load and light load) is around $300 \mathrm{~W}$. From those simulations, we found that the feeder length is one major impact factor on determination of the maximum allowable capacity of CRESs in the low voltage distribution system. 


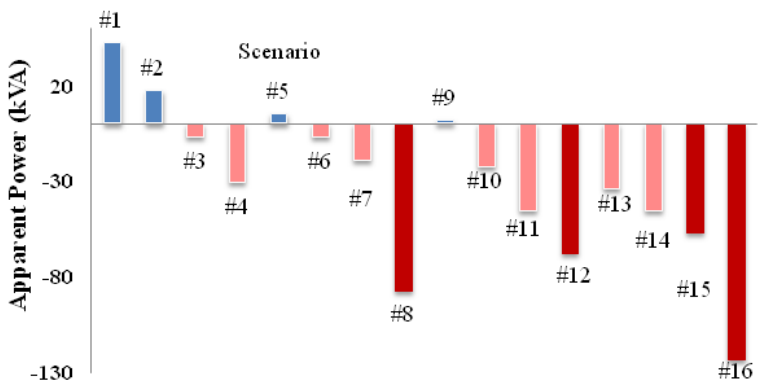

Fig. 5. Distribution transformer loading

Table 2 Simulation scenarios for the maximum allowable capacity of CRESs

\begin{tabular}{|c|c|c|c|}
\hline \multirow{2}{*}{$\begin{array}{c}\text { Load Arrangement } \\
\text { Line length }\end{array}$} & $\begin{array}{c}|c| \\
\text { Uniform } \\
\text { distribution }\end{array}$ & $\begin{array}{c}\text { Ascending } \\
\text { distribution }\end{array}$ & $\begin{array}{c}\text { Descending } \\
\text { distribution }\end{array}$ \\
\hline $95 \mathrm{~m}$ & Scenario \#1 & Scenario \#2 & Scenario \#3 \\
\hline $30 \mathrm{~m}$ & Scenario \#7 & Scenario \#8 & Scenario \#9 \\
\hline & \multicolumn{3}{|c|}{ Light Load } \\
\cline { 2 - 4 } & $\begin{array}{c}\text { Uniform } \\
\text { distribution }\end{array}$ & $\begin{array}{c}\text { Ascending } \\
\text { distribution }\end{array}$ & $\begin{array}{c}\text { Descending } \\
\text { distribution }\end{array}$ \\
\hline $95 \mathrm{~m}$ & Scenario \#4 & Scenario \#5 & Scenario \#6 \\
\hline $30 \mathrm{~m}$ & Scenario\#10 & Scenario \#11 & Scenario \#12 \\
\hline
\end{tabular}

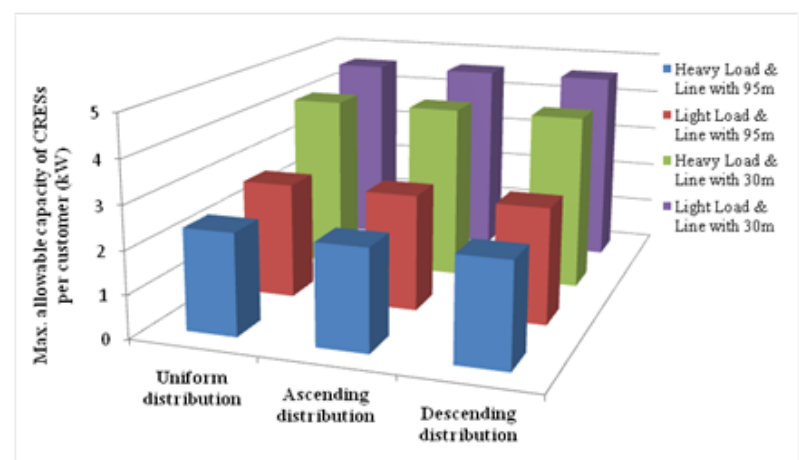

Fig. 6. Simulation Results for the maximum allowable capacity of CRESs

\section{CONCLUSION}

In this paper, the effects of clustered renewable energy systems (CRESs) on the low-voltage distribution system in Taiwan have been evaluated and discussed. The constantpower-factor model of DGs was used to perform the operating characteristic of DGs among CRESs. A direct search method is proposed to search for the maximum allowable capacity of CRESs in low voltage distribution system in Taiwan. Both of the interconnection rules for DGs and the national grid code are considering in this paper. Simulation results have shown that the arbitrary installation of CRESs would damage the customer loads and significantly increase the costs on system operation and maintenance. Those results are of value for power engineer and experts to plan and design a suitable clustered renewable energy systems (CRESs) in a low voltage distribution network.

\section{ACKNOWLEDGEMENTS}

The authors would like to thank the National Science Council of the Republic of China, Taiwan, for financially supporting this research under Contract No. NSC 101-2221-E$011-083$ -

\section{REFERENCES}

[1] R. Cossent, T. Gómez, and L. Olmos, "Large-scale integration of renewable and distributed generation of electricity in Spain: Current situation and future needs," Energy Policy, vol. 39, 2011, pp. 8078-8087.

[2] S. Wittkopf, S. Valliappan, L. Y. Liu, K. S. Ang, and S. C. J. Cheng, "Analytical performance monitoring of a $142.5 \mathrm{~kW}(\mathrm{p})$ grid-connected rooftop BIPV system in Singapore," Renewable Energy, vol. 47, Nov 2012, pp. 9-20.

[3] S. Morozumi, N. Inoue, Y. Arashiro, Y. Chiba, and T. Iwasaki, "Strategies and status of grid-connection Technology Development in NEDO," in Power and Energy Society General Meeting - Conversion and Delivery of Electrical Energy in the 21st Century, 2008 IEEE, 2008, pp. 1-6.

[4] R. Tonkoski, D. Turcotte, and T. H. M. El-Fouly, "Impact of High PV Penetration on Voltage Profiles in Residential Neighborhoods," Sustainable Energy, IEEE Transactions on, vol. 3, 2012, pp. 518-527.

[5] A. Woyte, V. Van Thong, R. Belmans, and J. Nijs, "Voltage fluctuations on distribution level introduced by photovoltaic systems," Energy Conversion, IEEE Transactions on, vol. 21, 2006, pp. 202-209. 